\title{
IoT: A Mobile Application and Multi-Hop Communication in Wireless Sensor Network for Water Monitoring
}

\author{
https://doi.org/10.3991/ijim.v14i11.13681
}

\author{
Budi Rahmadya ${ }^{(凶)}$, Zaini and Mumuh Muharam \\ Andalas University, Padang, Indonesia \\ Budi-refti.unand.ac.id
}

\begin{abstract}
In this research, we discuss the implementation of multi-hop communication in sending data regarding the temperature, humidity and the water quality of Maninjau Lake area by utilizing wireless sensor network (WSN) technology. Maninjau lake has seen a growth in fish farming in recent years, which has caused water pollution and high rates of fish mortality. The performance of the sensor node or the end device node in sending data to the coordinator needs to be maximized, so that the information is well received by the user. The result of the performance is not only related to the equipment's used, but also to the network topology and the communication model. In this study, we use multi-hop data communication technique using Zigbee S2 wireless module standard IEEE 802.15.4 and a router node on a mesh topology network. Data is received in real time by the coordinator and can be monitored via a mobile device connected to the internet using IoT (ESP 8266) module. The result of the simulation shows that each end device sends the data of temperature, humidity and the $\mathrm{PH}$ of water of Maninjau Lake to the router nodes and forwards them to the coordinator. Information can be accessed by the user through a mobile phone application. There are many potential applications for this research in monitoring water quality, preventing pollution and reducing aquaculture mortality.
\end{abstract}

Keywords - Mobile application, Multi-hop communication, wireless sensor network (WSN), Mesh topology, and IoT (ESP 8266) module.

\section{Introduction}

The Internet of Thing (IoT) has recently attracted significant research attentions from academia and researchers in research field such as monitoring system application. IoT technology can reduce of time efficiencies and support in monitoring system by using sensors. Furthermore, Fan, et. al [1] introduced a wearable body area network (WBAN) is developed for human safety in workplace and Syed, et. al [2] introduced emergencies monitoring application has introduced for saving human lives in warning situation.

In other hand, the technology of wireless sensor networks (WSNs) is being increasingly implemented over wide areas. Zigbee is one of the wireless communication modules used in WSN and it supports multi-hop communication. Zigbee is small in size and 
belongs to the low-cost wireless protocols section of the IEEE 802.15.4 standard. Zigbee technology is usually implemented for monitoring systems, such as for natural disasters, climate change, smart industry and others.

In order to work well, WSN needs to manage data communication between each node in a communication network. In addition, one of the challenges in implementing WSN technology in wide areas is the process of multi-hop communication in sending data from several sensor nodes to the IoT services. The end device node is placed at a certain distance and it transmits the data obtained from the coordinator. In this paper, we concentrate on maximizing the transmission of data from multiple sensor nodes (end devices) to the server using mesh topology for water monitoring application in Maninjau Lake, Indonesia. The communication model used is multi-hop communication.

\section{Literature Review}

Several researchers have discussed the multi-hop communication in WSN such as Nandini, et. al [3] use a query process to improve energy efficiency of the nodes demonstarting that energy consumption was much lower than direct data transmission. Otherwise Min, et. al [4] discuss data dissemination during communication density in wireless sensor networks. The simulations used two approaches: (1) cooperative mesh structure (CMS) construction, and (2) CMS-based data dissemination. The simulation results show that the concept of distributed multi-hop cooperative communication (DMC) works well in improving Quality of Service (QoS) and this can be implemented on a wide and dynamic network system. Xiang, et. al [5] introduce a distributed algorithm scheduling to reduce time latency and energy cost. Rasin, et. al [6] discuss water quality monitoring using sensor networks. These re-searchers focused on the condition of $\mathrm{pH}$, the turbidity and the temperature of the water. The purpose of this study was to improve the efficiency, the cost and to find out a more economical maintenance of water monitored wirelessly using Zigbee devices. Kim, et. al [7] introduced a monitoring and control system using Zigbee in real time. These researchers focused on the electrical energy management used at home. Applications designed are website and mobile-based and can control the use of electricity to reduce living costs. Janos, et. al [8] implemented a wireless network using ZigBee for a monitoring system of plant moisture on a green house. They used a mobile robot that functions as a station. In the simulation tool, information is sent through a broadcast. furthermore Dahoud, et. al [9] explored using Wireless Sensor Network (WSN) in sending data to the gateway to control air quality. The researchers tested the conditions of CO, NO2 and LPG. Sensor data can be accessed by the user in real time through the internet network. Garcia et. al [10] also analyzed the monitoring system for fruit freshness during its delivery. The researchers utilize wireless network technology to determine the freshness of the fruits by using Xbow and Xbee technology. Elankavi et. al [11] discuss the data collection techniques of several studies and emphasize the advantages and disadvantages of each study. 


\section{$3 \quad$ Material and Method}

In this study, the sensor nodes were placed at predetermined points in the area of Maninjau Lake to detect the quality of lake water. Maninjau lake has experienced repeated incidents of pollution and mass deaths of fish, which have been caused by poor water quality. The network topology used is mesh topology, and information delivery method used is multi-hop communication. Data were sent from each end devices to router nodes to be forwarded to the coordinator. The researchers also utilize the Internet of Things technology to maximize the performance of the equipment's in generating information. This information is accessed by the user through android applications that have been provided.

\subsection{Coordinator node}

The coordinator node functions to receive information from the end device nodes that are placed at some points that has been specified in the Maninjau Lake area. Coordinator node consists of the following components: arduino mega microcontroller, Xbee S2, real time clock, memory, ESP 8266, LCD and battery. Data are received in real time and are stored in memory that has been provided. Figure 1 shows the schematic of the coordinator node that was created.

Router node: The function of the router node is to maximize the range of wireless communications sent by the end device to the coordinator. Components of router node used in this study are arduino uno microcontroller, Xbee S2, Xbee shield and battery. Figure 2 shows the schematic of the router node that was created.

End device node: End device node functions to collect information on the water temperature, humidity and $\mathrm{pH}$ of Maninjau Lake. The components of the end device node in this study consist of arduino uno microcontroller, Xbee S2, Xbee shield, DHT 22 sensor, pH sensor and battery. Figure 3 shows the schematic of the created end device node.

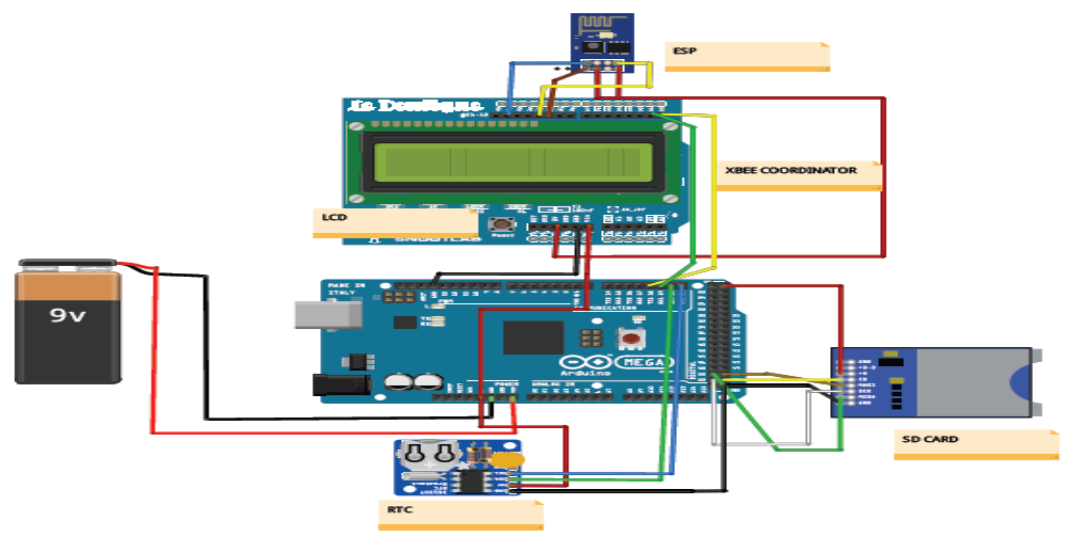

Fig. 1. Coordinator devices 


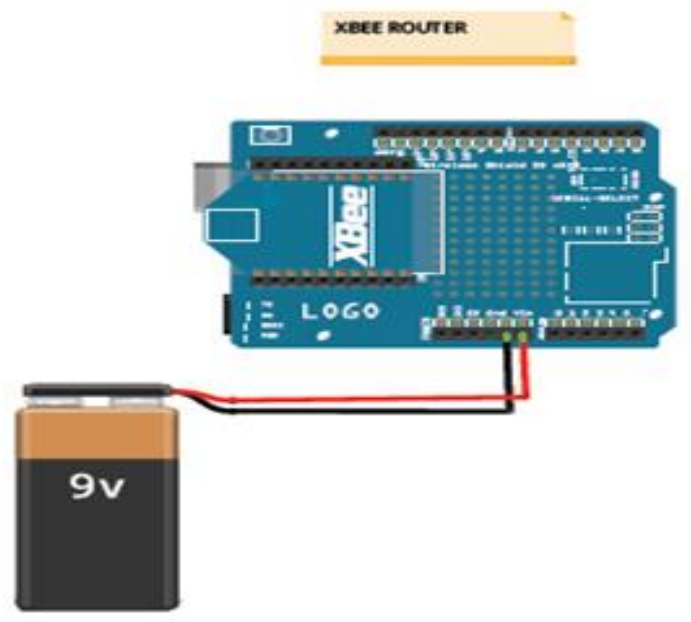

Fig. 2. Router devices

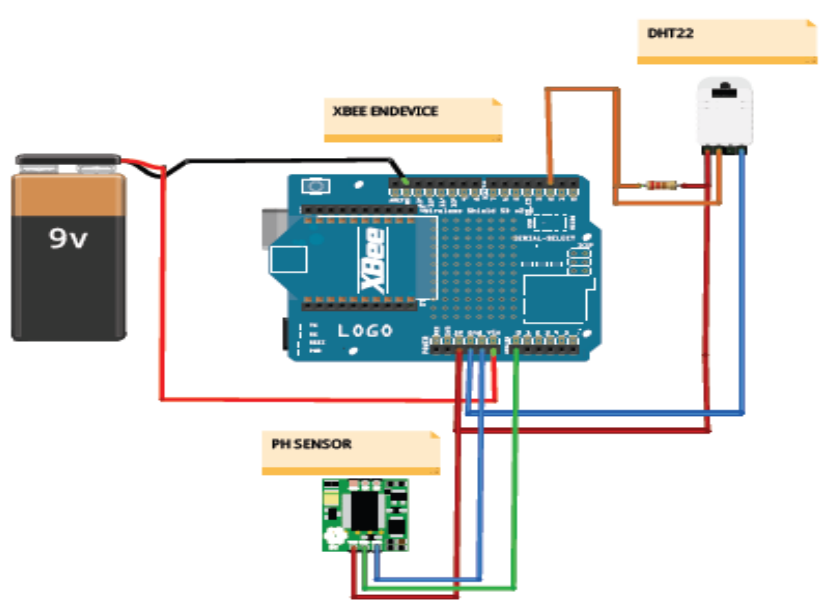

Fig. 3. End devices

Wireless Sensor Network (WSN): The communication model that can be used in a wide environment is WSN. In this research, we implement multi-hop communication. The discussion in this section is to test the performance of each node.

Internet of Things (IoT): Inside the IoT, an electronic device can communicate with other electronic devices independently. IoT can also be utilized for smart homes application. This research, we use IoT ESP 8266 module. The details on the research equipments specifications are shown in Table 1. 
Table 1. Research Equipments Specifications

\begin{tabular}{|l|l|}
\hline \multicolumn{1}{|c|}{ Item } & \multicolumn{1}{c|}{ Specification } \\
\hline Receiver & Arduino mega \\
\hline Transmitter & Arduino uno \\
\hline Shield & Xbee shield \\
\hline Wireless device & Xbee S2 standard antenna \\
\hline Battery & 9 volts \\
\hline IoT Modul & ESP 8266 \\
\hline Real Time Clock & DS1302 I2 ${ }^{\circ}$ C RTC \\
\hline SD Card & Micro SD \\
\hline Sensor & pH and DHT 22 \\
\hline Software & X-CTU, XML and Android Studio \\
\hline
\end{tabular}

Mesh Topology and Mobile Application Design: Multi-hop communication methods for wide areas can use mesh topology. The discussion done in this section is to test the performance of each sensor node to transmit data to the coordinator. Figure 4 below is the mesh topology in Maninjau Lake and figure 5 shown the mobile application design.

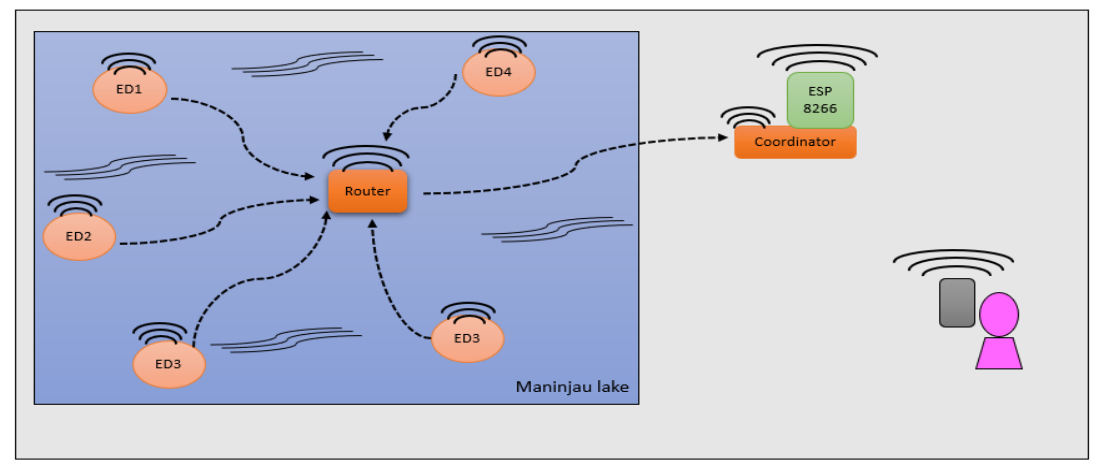

Fig. 4. Mesh topology

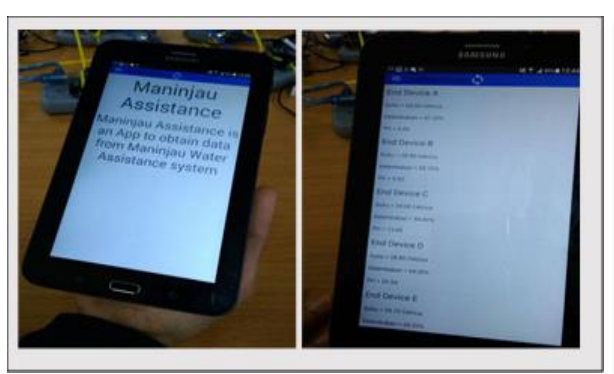

Information:

- This application named

Maninjau assistance

- The application is android based

- Data shown in real time

Fig. 5. Mobile application design 


\section{$4 \quad$ Result and Discussion}

a) DHT 22 sensor test

The DHT22 sensor test is to see the humidity and temperature conditions of Maninjau Lake. Data are taken in real time with humidity interval 0-80 and temperature interval 0-35. From the simulation has been done in obtaining data stored in memory as much as 44 times. The average sensor response in the humidity field is between 55.53 to 60.98 and the temperature between 26.18 to 28.88. Figures 6 and 7 below are DHT22 response to humidity and temperature.

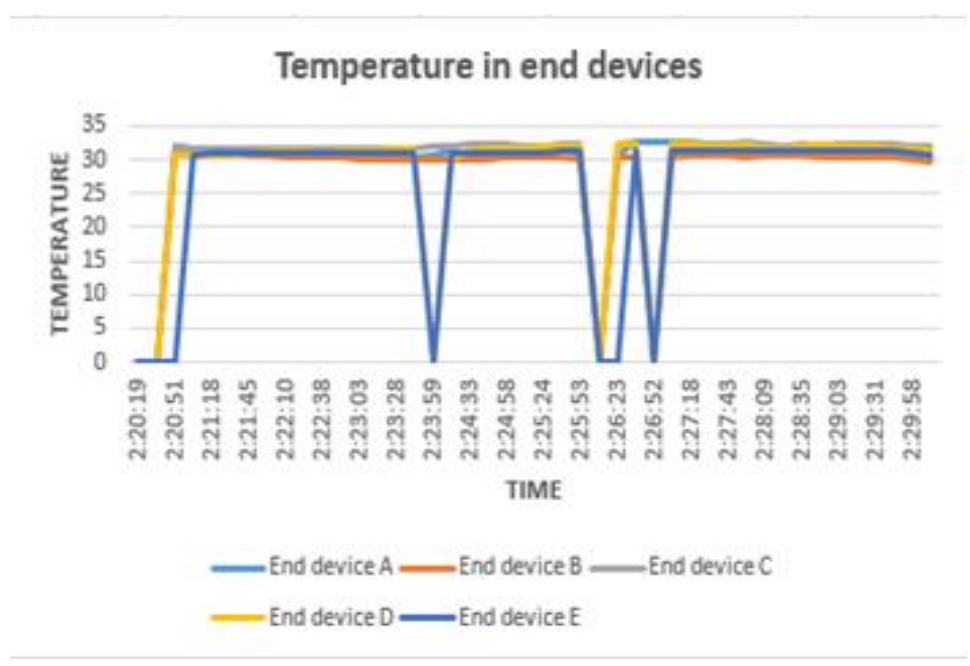

Fig. 6. Humidity in end devices

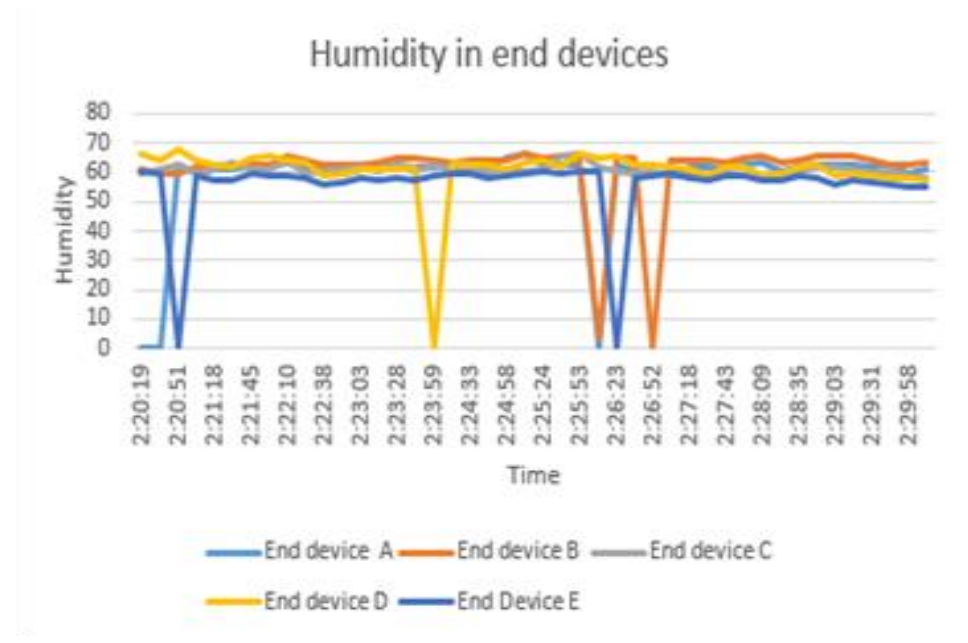

Fig. 7. Temperature in end devices 


\section{b) PH sensor test}

The PH sensor test is to see the water conditions of Maninjau Lake. Data are taken in real time with PH interval 0-6. The simulation show data stored in memory is 44 times and obtained the sensor response for the water PH condition between 3.58 to 4.69 . Figures 8 below are $\mathrm{PH}$ response in end devices.

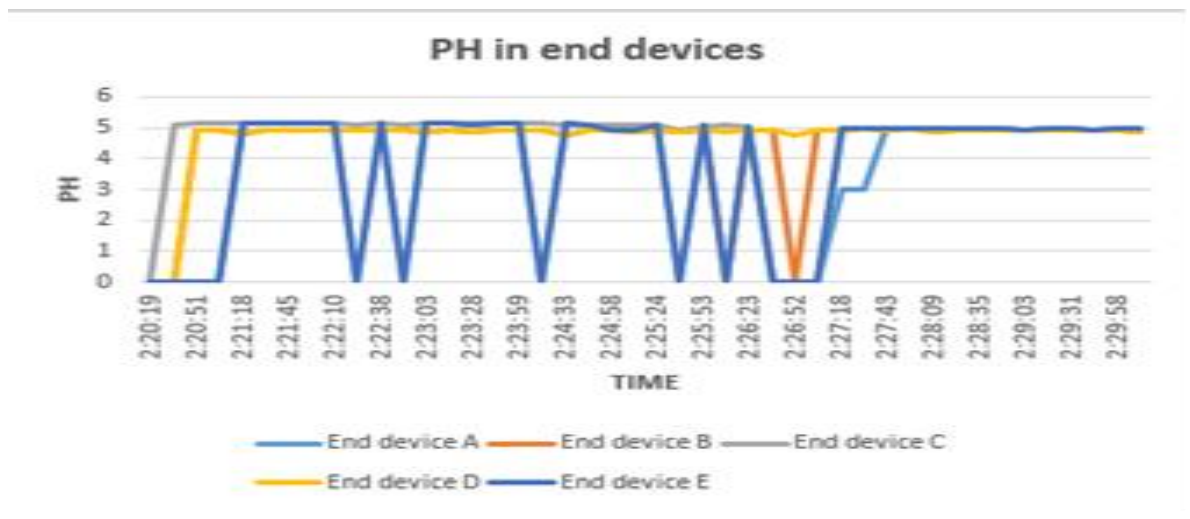

Fig. 8. PH in end devices

If seen from the graph of simulation result above, packet loss still happened during the simulation. This can be caused by the communication path density that occurs from the route of end device to the coordinator.

\section{Conclusion}

In this paper, we have discussed multi hop communication using wireless sensor network for cooperative data transmission in Maninjau Lake. The responses from each end device based on the data sent to the coordinator shows that the average result is 55.53 to 60.98 for humidity and 26.18 to 28.88 for the temperature. $\mathrm{pH}$ sensor test shows that the average $\mathrm{pH}$ of Maninjau Lake water is between 3.58 to 4.69. This research has important ecological and economic applications. Monitoring water quality remotely provides a cost-effective way of preventing pollution incidents and reducing the rate of fish mortality in the aquaculture industry. In order to reduce packet loss, further research is required by implementing distributed algorithms for near optimal channel allocation and localization techniques for each node. Additional work is extending the coverage of monitoring system by using LoRa technology and calculate the network communication performance in wide area simulation. 


\section{Acknowledgement}

We would like to express our gratitude to the Faculty of Information Technology of Andalas University, Indonesia for funding this research grant number 01/UN16.15/PL/FTI-Universitas Andalas.

\section{$7 \quad$ References}

[1] Fan, W., Taiyang, W., \& Mehmet, R. Y. (2018). An Internet-of-Things (IoT) Network System for Connected Safety and Health Monitoring Applications. Sensors Journal, vol. 9, issue 1, pp. 1-21, 2018. https://doi.org/10.3390/s19010021

[2] Syed, M., Junaid, A. Z., \& Abdul, R. A. (2018). IoT-Based Ambulatory Vital Signs Data Transfer System. Journal of Computer Networks and Communications, vol. 2018, pp. 1-8, 2018. https://doi.org/10.1155/2018/4071474

[3] Nandini. S. Patil., \& P. R. Patil. (2010). Data Aggregation in Wireless Sensor Network. 2010 IEEE International Conference on Computational Intelligence and Computing Research.

[4] Min, C., Meikang, Q., Linxia, L., Jongan P., \& Jianhua, M. (2011). Distributed multi-hop cooperative communication in dense wireless sensor networks. Springer, vol. 56. pp. 353369, 2011.

[5] Xiang, Y. Lit., XiaoHua, X., ShiGuang, W., ShaoJie, T., GuoJun, D., JiZhong, Z., \& Yong Q. (2009). Efficient Data Aggregation in Multi-hop Wireless Sensor Networks Under Physical Interference Model. 2009 IEEE 6th International Conference on Mobile Adhoc and Sensor Systems pp. 353-362, 2009. https://doi.org/10.1109/mobhoc. 2009.5336978

[6] Rasin, Z., \& Abdullah, M. R. (2009). Water Quality Monitoring System Using Zigbee Based Wireless Sensor Network. International Journal of Engineering \& Technology (IJET) vol. 9, no. 10.

[7] Kim, W. H., Lee, S., \& Hwang, J. (2011). Real-time Energy Monitoring and Controlling System based on ZigBee Sensor Networks. Elsevier, Procedia Computer Science vol. 5 pp. 794-797, 2011. https://doi.org/10.1016/j.procs.2011.07.108

[8] Janos, S., Martinovic, G., \& Matijevics, I. (2010). WSN Implementation in the Greenhouse Environment Using Mobile Measuring Station. International Journal of Electrical and Computer Engineering Systems, vol 1, no. 1, 2010.

[9] Dahoud, A. A., Fezari, M., Jannoud, I., \& Rawashdeh, A. T. (2015). Monitoring Metropolitan City Air-quality Using Wireless Sensor Nodes based on Arduino and Xbee. Proceedings of The International Conference on Circuits, Systems, Signal Processing, Communications and Computers (CSSCC 2015).

[10] Garcia, L. R., Barreiro, P., \& Robla, J. I. (2008). Performance of ZigBee-Based wireless sensor nodes for real-time monitoring of fruit logistics. Elsevier, Journal of Food Engineering vol. 87, pp. 405-415, 2008. https://doi.org/10.1016/j.jfoodeng.2007.12.033

[11] Elankavi, R., Udayakumar, R., \& Kalaiprasath, R. (2013). Data Collection in Wireless Sensor Networks -A Literature Survey. International Journal of Innovative Research in Computer and Communication Engineering, vol. 1, issue 5, 2013. 


\section{Authors}

Budi Rahmadya received the M.E. degree in computer science from Nara Institute of Science and Technology (NAIST), Japan, in 2013. He is a lecturer with Computer System Department, Faculty of Information Technology, Andalas University, Indonesia. His research interests include wireless communications, LPWAN, sensor network, networking and Internet of Things.

Zaini is a lecturer and researcher in Electrical Engineering Department, Faculty of Engineering, Andalas University, Indonesia. His current research interests include the Internet of Things and controls system.

Mumuh Muharam is a lecturer and researcher in Electrical Engineering Department, Faculty of Engineering, Andalas University, Indonesia. His current research interest is controls system.

Article submitted 2020-02-10. Resubmitted 2020-03-28. Final acceptance 2020-03-29. Final version published as submitted by the authors. 